\title{
The Application and Research of Ideational Grammatical Metaphor Theory in College English Writing Teaching
}

\author{
Wencui Gong \\ Jilin Institute of Chemical Technology \\ Jilin, China
}

\begin{abstract}
Metaphor is considered a form of speech in rhetoric, a way for people to recognize the world in cognitive linguistics, and a grammatical function in functional linguistics. The purpose of this paper is to explore the application of linguistics to the study of grammatical metaphors and to instruct college English writing.
\end{abstract}

Keywords-metaphor; ideational grammatic metaphor; college English writing

\section{INTRODUCTION}

Western scholars have held a variety of viewpoints on the study of metaphors. Metaphor was first studied as a rhetorical object dating back to the Aristotle era. As the first person to study metaphor theory in the West, Aristotle thought that metaphor is the transfer or replacement of names, so he classifies metaphors as a kind of rhetoric, aiming to make words more euphemistic and elegant. Baekman further supplements that metaphor can make words more interesting. Tepper believes that metaphor can achieve a shift in meaning through a substitution mechanism. The traditional linguistic view holds that metaphor is a deviation from normal linguistic phenomena and is either wrong or ungrammatical. However, in the modern era, whether western philosophers, linguists or psychologists have found and proposed that metaphor is not only a rhetorical device, but also a way of thinking. Specifically, metaphors can help people to learn new things and to learn concretely. Lakoff and Johnson first proposed that metaphor had a cognitive function. The essence of metaphor is a kind of cognitive phenomenon, rather than a simple linguistic phenomenon considered in traditional viewpoints. However, in 1980, the publication of the book, which was about the metaphorical theories, and written by American cognitive linguists Lakoff and Johnson, namely "Metaphors We Live by" marked the transformation of metaphor research from traditional objectivism to cognitivism. In the second half of the 20th century, linguists represented by Halliday proposed the theory of systemic functional linguistics. This theory has become one of the most influential theories in linguistics. It not only helps language workers to interpret language in depth, but also has the incomparable vitality that other linguistic theories do not have.

\section{IDEATIONAL GRAMMATIC METAPHOR THEORY}

In 1985, Halliday created the theory of grammatical metaphor. As an important component of systemic functional linguistics, grammatical metaphor theory is different from metaphor theory under the framework of cognitive linguistics, and it is different from the definition of metaphor in traditional rhetoric. Halliday divides grammatical metaphors into "ideational metaphors" and "interpersonal metaphors".

The main manifestations of ideational metaphor are transitive ideational metaphor and nominalized ideational metaphor, which is to express the process or trait that should be expressed by verb or adjective in noun form. The main linguistic form of interpersonal metaphor is to express the tone and modality of the sentence in the form of a proposition, which should be expressed by the adverb.

In the early 1990s, the theory of grammatical metaphor began to be introduced to the country and it was gradually promoted and valued. Many scholars have studied grammatical metaphor from a theoretical perspective. However, this theory has not received due attention in the practice of foreign language teaching in China. Only a few scholars have discussed the application value of grammatical metaphor in college English teaching. Yang Xiaoying and others explored the role of ideational grammatical metaphor in English teaching and put forward the necessity of introducing grammatical metaphor into adult English teaching. Sun Chengrong and others conducted an empirical study of the relationship between ideational grammatical metaphor and students' discourse construction. They point out that grammatical metaphor is not only derived from the development of meaning, but also the product of the improvement of education and cognitive level. There is a certain correlation between the type of grammatical metaphor and the discourse type. Xiong Xueliang examined the use of grammatical metaphors in students' second language writing and reached the conclusion: in the second language acquisition, learners follow the law of transition from a uniform pattern to a metaphorical pattern in the individual development of grammatical metaphor. In particular, some low-level learners do not use the metaphorization of the organizational experience they have 
acquired in their mother tongue to apply to the target language because of their language level. Instead, they use more consistent expressions to express their ideas.

\section{The CURRENT SituAtion OF COLLEGE ENGLISH WRITING TEACHING}

In the process of traditional college English writing teaching, Chinese college English teachers mostly use resultbased teaching methods based on behaviorism theory. This kind of traditional writing teaching method is mainly expressed as a kind of single communication mode of "student writes himself, teacher reads alone". For students, writing is a one-time behavior. Most students regard the first draft as a finished product, and they cannot independently obtain constructive improvement measures from teachers' evaluation. Most students only pursue the teacher's guidance from the use of single words and grammar, but they do not get real help and helpful revelations.

On the other hand, because of the poor language environment, low level of teachers, and limited teaching equipment, especially the outdated teaching concepts, teaching methods and evaluation methods, the speed of improving the quality of college English teaching cannot meet the needs of social development. There are many timeconsuming and low-efficiency phenomena in English teaching. College English writing has become the most difficult course for English teachers in colleges and universities, and it is also a course with poor effect.

In the Internet era, some students apply online ready templates to complete writing assignments for teachers. It cannot be denied that it does have a certain role, but it can only solve temporary needs. Students cannot use wellaccepted vocabularies, can't write decent phrases, and do not pay attention to analyzing the internal convergence of chapters, resulting in confusion and lack of logic. Their writing levels are in sharp contrast to the years of learning English. It can even be said to be disproportionate.

\section{THE APPLICATION OF IDEATIONAL GRAMMAR THEORY IN COLLEGE ENGLISH WRITING TEACHING}

\section{A. Activate Learners' Ideational Metaphor Mechanism}

Chinese English learners have been focusing on grammar learning during their growth. They should have entered the stage of ideational grammar metaphor with the improvement of their education, but their ideational grammar metaphor mechanism has not been activated. Therefore, they can only express their feelings with the help of consensus, making the language more subjective and straightforward. However, relevant data show that once the learner's ideational metaphor mechanism is activated, it can greatly improve the learner's use of noun structure, metaphorical metaphor, passive sentence, etc., and greatly promote their English writing ability.

\section{B. Change Learners' Language Structure}

Writing is actually the process by which the author uses his own ideas as a material to create works through language.
This kind of creation, like architectural design, requires rigorous logic and complete structure; otherwise it will result in the incompleteness of the work. The ancients still had "When choosing poems for their own sake, they had to think for a long time and even cut off a few beards." and "Three years are spent to think of two sentences, which is very moving". This shows the hardships of writing. Due to the influence of native language usage habits, they always use their native language habits to express the target language. This makes their English expressions non-comprehensive, which is apparent in their written language. It is particularly evident that students fully understand the lack of understanding of the correct expression of the target language. Metaphor theory reveals the similarities between human metaphorical thinking and language development. Metaphor is a manifestation of a national language and culture, and it is the most closely related part of language with culture. People will have the potential to understand other language metaphorical systems after they acquire the mother tongue and native language metaphor systems, but this kind of translation understanding is sometimes positive and sometimes negative. In teaching, teachers should consciously import the metaphorical system of the target language, cultivate their cross-cultural metaphorical ability, change their inherent linguistic structure, understand, accept, and learn to apply the metaphorical system of the target language so that they will gradually reduce the "Chinese Expression".

\section{Improve Learners' Metaphor Ability}

To improve students' ability to express English writing using ideational grammar metaphor is the key to English writing teaching. As students' level of education increases, their English level will increase accordingly, and the frequency of using metaphorical sentences will increase. Therefore, in the English writing class, teachers should teach the students the necessary theoretical grammatical metaphor theory knowledge to improve students' understanding of ideational grammar metaphor and improve their English writing quality. Therefore, teachers can start improving the students' ability of conceptual grammar metaphor in English writing.

- In English writing teaching, teachers should explain the concept of ideational grammatical metaphor, classification, metaphor expression and other concepts to students in a simple and easy way, so that students can understand the difference between metaphor in rhetoric and ideational grammar metaphor. It mainly occurs at the lexical level, while the latter mainly occurs at the grammatical level. Teachers should contrast the consistent and metaphorical language expressions so that students can deeply understand the way they convert each other, that is, enable students to understand and grasp the concrete process of verbalization, nominalization, and adjectivalization. In actual English writing teaching activities, 3P (presentation-practiceproduction) teaching methods can be adopted in order to improve the students' ability to use science 
metaphorically and reasonably, and finally to improve students' English comprehension and English writing skills.

- In the process of English writing teaching, teachers should organically combine theory study with writing practice. First, design practice exercises such as adjectives, adverbs, verbs, conjunctions, and other word-derived derivatives, and organize and summarize the nouns that express conditions, cause and effect, concessions, and related lexical meanings, as well as verbs and nouns that are frequently used as well as adjective sentence patterns. For example, turn of importance into important, turn valuable into of value, turn greatly happily into with great happiness, turn when seeing something into at the sight of and turn hope into in the hope of, etc. This kind of exercise can not only effectively expand the students' vocabulary chain, but also lay a foundation for grammatical metaphor exercises. Second, teachers should create opportunities for metaphorical expressions and consistent expression transformation exercises at the compound sentence level and the clause level, i.e., synonymous sentence conversions for related nominalization, verbalization, and adjectiveization. The above exercises can test students' grasp of grammatical metaphor concepts and types of understanding and so on. When designing the above exercises, teachers should try to start from the articles that the students had previously studied or are familiar with, so as to enhance students' perceptual knowledge and enthusiasm for English writing, and make active contributions to students' effective application of grammatical metaphor theory in English writing.

\section{CONCLUSION}

The training of grammatical metaphor can make students' English proficiency no longer simply remain on the surface of language ability, which is the fundamental way to approach the level of native speakers. The improvement of the level of writing is not an overnight task. However, improving students' grammatical metaphor from the aspect of writing can reduce their anxiety in the process of writing and can better feel the charm of language, which in turn can greatly improve students' English writing skills.

\section{REFERENCES}

[1] Halliday, M. A. K. An Introduction to Functional Grammar [M]. London: Edward Arnold, 1994.

[2] Halliday, M. A. K. \& R. Hasan. Cohesion in English [M]. Beijing: Foreign Language Teaching and Research Press, 2007.

[3] Halliday, M. A. K. Spoken and Written Language [M]. Victoria: Deakin University Press, 1985.

[4] Kroll, B. Second Language Writing Research for the Classroom [M]. Cambridge: Cambridge University Press, 1994.

[5] Martin , J.R. English Text [M] Philadelphia: John Benjamin Publishing Company, 1992.
[6] Nunan, D. Second Language Teaching and Learnin. [M]. Boston: Heinland Heinle Publishers, 1999.

[7] Ortony, A. Metaphor and Thought [M]. Cambridge University, 1979. 